\section{Vaccines for post-exposure prophylaxis against \\ varicella (chickenpox) in children and adults}

\author{
Kristine Macartney, Peter Mclntyre \\ The independent commentary was written by Helena Keico Sato
}

\begin{abstract}
BACKGROUND: Live attenuated varicella vaccines for the prevention of varicella (chickenpox) has been demonstrated both in randomised controlled trials (RCTs) and in population-based immunisation programmes in countries such as the United States. However, many countries do not routinely immunise children against varicella, and exposures continue to occur. Although the disease is often mild, complications such as secondary bacterial infection, pneumonitis and encephalitis occur in about $1 \%$ of cases, usually leading to hospitalisation. The use of varicella vaccine in persons who have recently been exposed to the varicella zoster virus has been studied as a form of post-exposure prophylaxis (PEP).

OBJECTIVE: To assess the efficacy and safety of vaccines for use as PEP for the prevention of varicella in children and adults.

CRITERIA FOR CONSIDERING STUDIES FOR THIS REVIEW: We searched the Cochrane Central Register of Controlled Trials (CENTRAL) (The Cochrane Library, 2008, Issue 1); MEDLINE (1966 to February 2008); and EMBASE (January 1990 to February 2008).

SELECTION CRITERIA: RCTs and quasi-RCTs of varicella vaccine for PEP compared with placebo or no intervention. The outcome measures were efficacy in prevention of clinical cases and/or laboratory-confirmed clinical cases and adverse effects following vaccination.

DATA COLLECTION AND ANALYSIS: Two review authors independently extracted and analysed data using Review Manager software.

MAIN RESULTS: Three studies involving 110 healthy children who were siblings of household contacts were identified as suitable for inclusion. The studies varied in quality, study design, vaccine used, and outcomes measured and, as such, were not suitable for meta-analysis. Overall, 13 out of 56 vaccine recipients (18\%) developed varicella compared with 42 out of 54 placebo (or no vaccine) recipients (78\%). Of the vaccine recipients who developed varicella, the majority only had mild disease (with less than 50 skin lesions). In the three studies, most subjects received PEP within three days following exposure; too few subjects were vaccinated four to five days post exposure to ascertain the efficacy of vaccine given more than three days after exposure. No included studies reported on adverse events following immunisation.

AUTHORS CONCLUSIONS: These small trials suggest varicella vaccine administered within three days to children following household contact with a varicella case reduces infection rates and severity of cases. No RCTs for adolescents or adults were identified. However safety was not adequately addressed.
\end{abstract}

This is the abstract of a Cochrane Review published in the Cochrane Database of Systematic Reviews (CDSR) 2011, ISSUE 08, DOI: 10.1002/14651858.CD001833.pub3 (www.thecochranelibrary.com). For full citation and authors details, see reference 1 .
For Latin America and the Caribbean, the full text is freely available from: http://cochrane.bvsalud.org/cochrane/show.php?db=reviews\& $\mathrm{mfn}=932 \& \mathrm{id}=\mathrm{CD} 001833 \&$ lang $=p t \& \mathrm{dblang}=\& \mathrm{lib}=\mathrm{COC} \&$ print $=$ yes

\section{REFERENCE}

1. Macartney K, Mclntyre P. Vaccines for post-exposure prophylaxis against varicella (chickenpox) in children and adults. Cochrane Database Syst Rev. 2008;(3):CD001833.

\section{COMMENTS}

Varicella zoster infection is caused by the varicella-zoster virus (VZV), which is transmitted by direct contact from person to person through vesicle fluid or aerosols. The mean incubation period is 14 days, ranging from 10 to 21 days, and the transmission period is from one or two days before the rash appears to five days after it appears or until crusting of all lesions. People who acquire this infection generally have a good outcome, but about $5 \%$ may develop complications such as secondary bacterial infections, upper and lower airway infections and, rarely, encephalitis. 'The varicella vaccine is not yet available within the universal childhood immunization program in Brazil.

The varicella vaccine can be administered to children within three days following household contact with a varicella case, thereby reducing the infection rate and severity of cases. ${ }^{2}$

It is very important to use varicella vaccine as a post-exposure prophylaxis measure for susceptible contacts, because when applied within 72 hours, it prevents or attenuates the disease. This measure can also be used for household contacts and for people in other environments such as nurseries and hospitals for whom there is no evidence of immunity. In the Brazilian Ministry of Health's Handbook of Special Immunobiological Reference Centers, ${ }^{3}$ it is recommended that post-exposure prophylactic vaccine is applied as soon as is possible, and within 120 hours after infection. In these Reference Centers, varicella vaccine is available for controlling hospital outbreaks among children over the age of one year. For pregnant women and immunocompromised patients, specific passive immunoprophylaxis is administered as soon as possible, and within 96 hours.

Helena Keico Sato, PhD. Director of the Immunization Program of the "Professor Alexandre Vranjac" Epidemiological Surveillance Center, State of São Paulo Health Department.

\section{REFERENCES}

1. Marin M, Güris $D$, Chaves SS, et al. Prevention of varicella: recommendations of the Advisory Committee on Immunization Practices (ACIP). MMWR Recomm Rep. 2007;56(RR-4):1-40.

2. Macartney K, McIntyre P. Vaccines for post-exposure prophylaxis against varicella (chickenpox) in children and adults. Cochrane Database Syst Rev. 2008;(3):CD001833.

3. Brasil. Ministério da Saúde. Secretaria de Vigilância em Saúde. Departamento de Vigilância Epidemiológica. Manual dos centros de referência para imunobiológicos especiais. Brasília: Ministério da Saúde; 2006. Available from: http://portal.saude.gov.br/portal/ arquivos/pdf/livro_cries_3ed.pdf. Accessed in 2011 (Dec 8). 